Provided for non-commercial research and education use. Not for reproduction, distribution or commercial use.

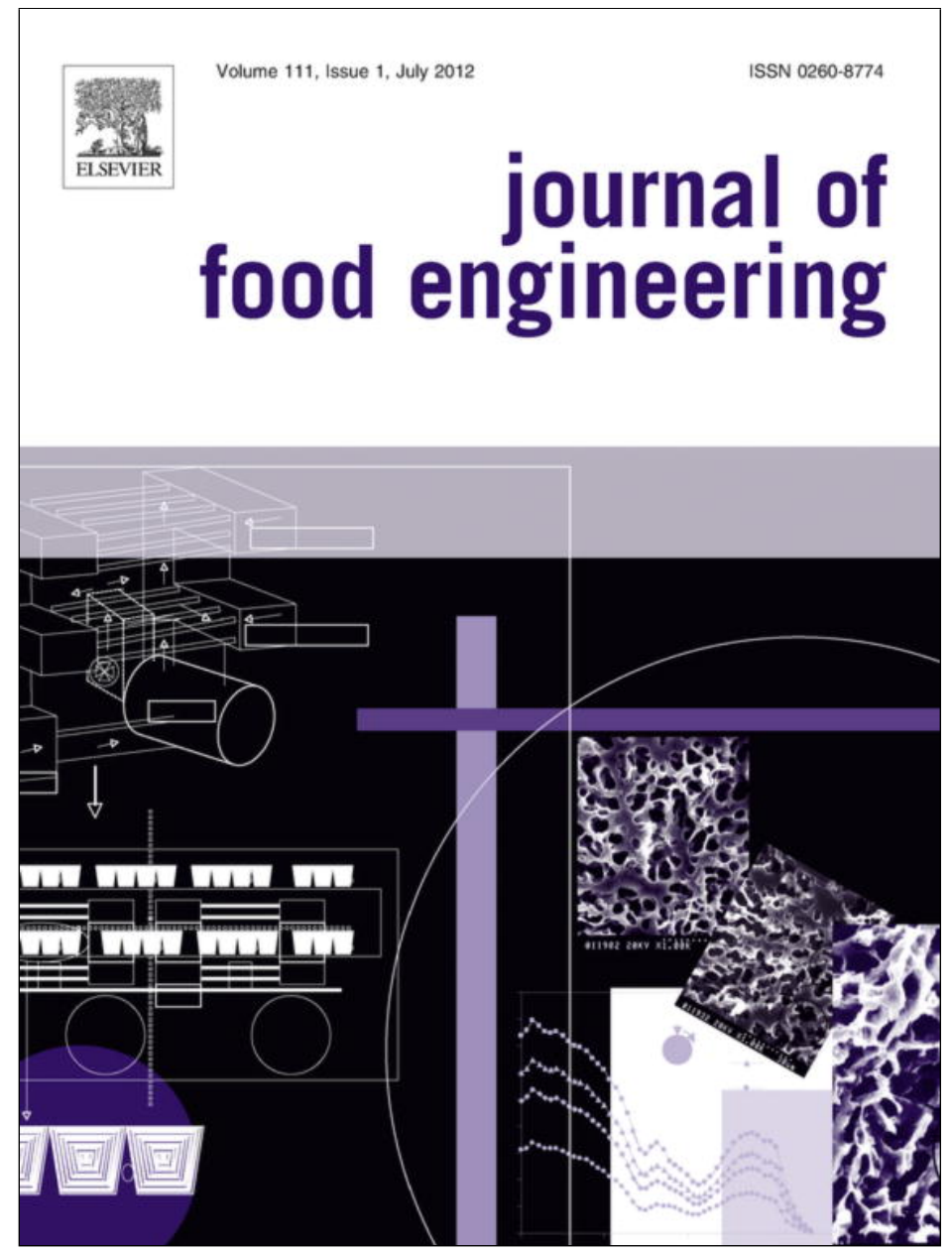

This article appeared in a journal published by Elsevier. The attached copy is furnished to the author for internal non-commercial research and education use, including for instruction at the authors institution and sharing with colleagues.

Other uses, including reproduction and distribution, or selling or licensing copies, or posting to personal, institutional or third party websites are prohibited.

In most cases authors are permitted to post their version of the article (e.g. in Word or Tex form) to their personal website or institutional repository. Authors requiring further information regarding Elsevier's archiving and manuscript policies are encouraged to visit:

http://www.elsevier.com/copyright 


\title{
Lab and pilot-scale ultrasound-assisted water extraction of polyphenols from apple pomace
}

\author{
Daniella Pingret, Anne-Sylvie Fabiano-Tixier, Carine Le Bourvellec, Catherine M.G.C. Renard, \\ Farid Chemat*
}

INRA, UMR408 Sécurité et Qualité des Produits d'Origine Végétale, F-84000 Avignon, France

Université d'Avignon et des Pays de Vaucluse, UMR408 Sécurité et Qualité des Produits d'Origine Végétale, F-84000 Avignon, France

\section{A R T I C L E I N F O}

\section{Article history:}

Received 7 August 2011

Received in revised form 23 January 2012

Accepted 26 January 2012

Available online 6 February 2012

\section{Keywords:}

Caffeoylquinic acid

Flavonols

Malus $\times$ domestica Borkh

Procyanidin

Ultrasound

Water extraction

\begin{abstract}
A B S T R A C T
Apple pomace, a residue from juice or cider production, shows high content of exploitable polyphenols. In this work, apple pomace was submitted to an Ultrasound-Assisted Extraction (UAE) in order to produce extracts rich in antioxidants. After a preliminary study, a solid/liquid ratio of $150 \mathrm{mg}$ of dry material per $\mathrm{mL}$ was used, and optimized conditions obtained by response surface methodology for polyphenols water-extraction were $40{ }^{\circ} \mathrm{C}, 40 \mathrm{~min}$ and $0.764 \mathrm{~W} / \mathrm{cm}^{2}$. A comparison showed Total Phenolics Content (TPC) obtained by UAE was 30\% higher than the content obtained by Conventional Extraction (CE)(555 and $420 \mathrm{mg}$ of catechin equivalent per $100 \mathrm{~g}$ of dry weight, respectively) and both methods presented the same extraction kinetics. Furthermore, extracts obtained by ultrasound showed higher antioxidant activity, which was confirmed by HPLC analysis, that revealed main polyphenols were not degraded under the applied conditions. The large scale experiments of this ultrasound procedure showed a potential industrial application.
\end{abstract}

(C) 2012 Elsevier Ltd. All rights reserved.

\section{Introduction}

Apples (Malus $\times$ domestica Borkh.) are known to contain many types of phenolic acid derivatives and flavonoids with high nutritional value, which are present particularly at high concentrations in cider apples (Sanoner et al., 1999; Wijngaard and Brunton, 2010). Apple pomace, the solid waste resulting from industrial processing of apple juice or cider production, is rich in extractable polyphenols (Cao et al., 2009; Cetkovic et al., 2008; Kołodziejczyk et al., 2009; Virot et al., 2010). The quality and amount of pomace produced (which can represent $20-30 \%$ of the weight of processed apples) is directly related to the technology used in the apple juice extraction. The polyphenols extracted from apples present numerous biological activities, such as antiallergic activity (Akiyama et al., 2000; Kanda et al., 1998), in vivo anticaries activity (Yanagida et al., 2000), and in vitro and in vivo inhibitory activity against some enzymes and receptors (Shoji et al., 2000).

Some of the polyphenols in the apple pomace present a high exploitable industrial potential as dietary or food antioxidant, exhibiting 2-3 times DPPH-scavenging activity and 10-30 times superoxide scavenging activity compared to vitamins $\mathrm{C}$ and $\mathrm{E}$ ( $\mathrm{Lu}$ and Foo, 1997; Lu, 2000). Polyphenols in apple pomace also showed antiviral properties against Herpes simplex virus from methanolic

\footnotetext{
* Corresponding author.

E-mail address: farid.chemat@univ-avignon.fr (F. Chemat).
}

extracts (Suárez et al., 2010). The safety of those polyphenols has also been evaluated and confirmed (Shoji et al., 2004). The content of phenolic compounds in the pomace is higher than the content in the juice and varies amongst different varieties of apples (Guyot et al., 1998, 2003; Cetkovic et al., 2008; Van der Sluis et al., 2002; Price, 1999; Kołodziejczyk et al., 2009). The main polyphenol class in apple pomace is procyanidins. The hydroxycinnamic acid derivatives are mainly represented by chlorogenic acid (5'-caffeoylquinic acid). Phloridzin (major constituent of dihydrochalcones) was thought to be a specific component to apples (Mangas et al., 1999), however, further studies have shown this compound is also present in strawberries (Hilt et al., 2003). Compared to the apple fruit, apple pomaces are richer in procyanidins, due to interactions with the polysaccharides (Le Bourvellec et al., 2007), and in flavonols and dihydrochalcones due to their location in the peel and pips, respectively (Guyot et al., 1998); in addition, they contain lower concentrations of hydroxycinnamic acids and catechins.

Ultrasound has been used for various processes in the chemical and food industry. The technique is fast, consumes less fossil energy and permits the reduction of solvents, thus resulting in a more pure product and higher yields. This method has been applied to extract food components such as aromas (Caldeira et al., 2004; Xia et al., 2006), antioxidants (Ma et al., 2009; Rodrigues et al., 2008; Wang et al., 2008; Virot et al., 2010), pigments (Chen et al., 2007; Barbero et al., 2008) and other organic and mineral components from a variety of matrices. Ultrasound plays an important role as real potential 
sustainable technique for industrial applications for polyphenols extraction (Khan et al., 2010). The cavitation process that occurs during sonication causes the rupture of cell walls, consequently enhancing solvent contact with available extractable cell material (Vinatoru, 2001).

The purpose of the present work was to evaluate the effects of ultrasound-assisted extraction of polyphenols obtained from dried apple pomace using an aqueous buffer as extraction solvent at mild temperatures. The extraction conditions (ultrasound intensity, temperature and extraction time) were optimized in order to obtain optimum polyphenol content using a response surface methodology. Comparative studies between ultrasound and conventional maceration were done for extraction kinetics, antioxidant tests such as lipid peroxidation activity and treating large amount for large scale experimentations. Finally, ultrasound effect on polyphenols molecules was also evaluated for three isolated polyphenolic compounds in order to verify the innocuousness of ultrasound technology.

\section{Materials and methods}

\subsection{Plant material and chemicals}

Apple pomace was obtained from Val-de-Vire Bioactives (Conde-sur-Vire, France) and kept in the dark until use. Standards of chlorogenic acid, (-) epicatechin and phloridzin, were purchased from Sigma Aldrich (St. Louis, USA). Other chemicals were of analytical grade and purchased from VWR International (Darmstadt, Germany).

\subsection{Extraction procedures}

In all extraction procedures, a $50 \mathrm{mM}$ malate buffer in a $\mathrm{pH} 3.8$ was used in order to mimetize fruit's conditions. To determine the optimal extraction conditions, the solid/liquid ratio was evaluated in function of total polyphenols obtained by a conventional maceration method. The samples subjected to extraction ranged from 5 to $35 \mathrm{~g}$ of dry material. The experiments were performed in flasks containing $100 \mathrm{~mL}$ of the buffer in a RT-10 magnetic stirrer plate (IKAMAG, Germany) over $8 \mathrm{~h}$ in the dark. Samples were then pressed using a manual press and filtered before analysis with a $0.45 \mu \mathrm{m}$ mesh filter. The total polyphenols content (TPC) was measured using Folin-Ciocalteau's reagent and results are expressed in $\mathrm{mg}$ of catechin equivalent per $100 \mathrm{~g}$ of dry weight. All experiments were carried out in triplicates.

Ultrasound-assisted extractions (UAE) were performed in an ultrasonic extraction reactor PEX1 (R.E.U.S., Contes, France) with $14 \times 10 \mathrm{~cm}$ internal dimensions and maximal capacity of $1 \mathrm{~L}$, equipped with a transducer at the base of jug operating at a frequency of $25 \mathrm{kHz}$ with maximum input power (output power of the generator) of $150 \mathrm{~W}$. The double-layered mantle (with water circulation) allowed the control of extraction temperature by cooling/heating systems. Considering the actual input power from the device is converted to heat which is dissipated in the medium, calorimetric measurements were performed to assess actual ultrasound power, calculated as shown in the Eq. (1) below (Toma et al., 2011).

$P=m \cdot C_{p} \cdot \frac{d \mathrm{~T}}{d \mathrm{t}}$

Where $C p$ is the heat capacity of the solvent at constant pressure $\left(\mathrm{J} \mathrm{g}^{-1}{ }^{\circ} \mathrm{C}^{-1}\right), m$ is the mass of solvent $(\mathrm{g})$ and $d T / d t$ is temperature rise per second. Then, the applied ultrasonic intensity (UI) was calculated using the calculated power as shown in the Eq. (2).(Tiwari et al., 2008).
$U I=\frac{4 P}{\pi D^{2}}$

Where $U I$ is the ultrasonic intensity $\left(\mathrm{W} \mathrm{cm}^{-2}\right), P$ is the ultrasound power (W) as calculated by the equation 1 , and $D$ is the internal diameter $(\mathrm{cm})$ of the ultrasound reactor. To the $500 \mathrm{~mL}$ of malate buffer ( $50 \mathrm{mM} \mathrm{pH} 3.8$ ), $75 \mathrm{~g}$ of dried apple pomace were added and submitted to extraction and the obtained extracts were filtered with a $0.45 \mu \mathrm{m}$ mesh filter before been lyophilized (for HPLC analysis) or analyzed for TPC. Conventional extraction was performed by agitation in the same conditions for comparison. All experiments were carried out in triplicates.

\subsection{Isolated compounds study}

In order to verify whether antioxidants present in the extracts undergo degradation during sonication, the following isolated compounds were submitted to ultrasound treatment: (-) epicatechin, phloridzin and chlorogenic acid. These compounds (in a final concentration of $0.5 \mathrm{mg} / \mathrm{mL}$ ) were diluted in $2 \mathrm{~mL}$ of methanol and then introduced in the ultrasonic extraction reactor with $200 \mathrm{~mL}$ of ma-

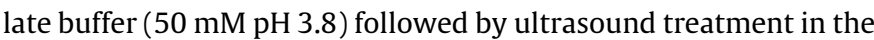
optimized conditions. The extractions were subsequently observed in the UV spectrophotometer (Spectronic Genesys 5, Thermo Fischer Scientific, France) at respective characteristic wavelengths for each molecule and then analyzed by HPLC-DAD for quantification purposes. All experiments were carried out in triplicates.

\subsection{Total phenolics determination (TPC)}

TPC was determined using Folin-Ciocalteau reagent (Singleton and Rossi, 1965). In a test tube, $50 \mu \mathrm{L}$ of the filtered sample were mixed with $1 \mathrm{~mL}$ of a $10 \% \mathrm{Na}_{2} \mathrm{CO}_{3}$ solution and $250 \mu \mathrm{L}$ of Folin-Ciocalteau reagent. The absorbance was determined using a spectrophotometer (Spectronic Genesys 5, Thermo Fischer Scientific, France) after $1 \mathrm{~h}$ at $765 \mathrm{~nm}$ against a calibration curve. The results were expressed in $\mathrm{mg}$ of catechin equivalent per $100 \mathrm{~g}$ of dry weight.

\subsection{Identification of phenolic compounds by HPLC-DAD}

Polyphenols were measured by HPLC after re-dissolution of the freeze-dried extracts in acidic methanol ( $1 \%$ acetic acid, v/v), or after thioacidolysis as described previously (Guyot et al., 2001), followed by filtration (PTFE, $0.45 \mu \mathrm{m}$ ). A Waters HPLC apparatus (Milford, MA, USA) was used, a system 717 plus autosampler equipped with a cooling module set at $4{ }^{\circ} \mathrm{C}$, a $600 \mathrm{E}$ multisolvent system, a 996 photodiode array detector, and a Millenium 2010 Manager system. The column was a Purospher RP18 endcapped, $5 \mu \mathrm{m}$ (Merck, Darmstadt, Germany). The solvent system was a gradient of solvent A (aqueous acetic acid, $25 \mathrm{~mL} / \mathrm{L}$ ) and solvent $\mathrm{B}$ (acetonitrile): initial, 3\% B; 0-5 min, 9\% B linear; 5-15 min, 16\% B linear; 15-45, 50\% B linear, followed by washing and reconditioning the column. HPLC peaks were identified on chromatograms according to their retention times and their UV-visible spectra by comparison with available standard compounds as described by Guyot et al. (2001). Quantification is performed by reporting the measured integration area in the calibration equation of the corresponding standard. Phloretin and phloretinxyloglucoside were calculated as phloridzin equivalent, all flavonols were quantified against quercetin (molar responses, then their respective contents of glycosides are used to calculate concentrations in $\mathrm{g} / \mathrm{L}$ or $\mathrm{g} / \mathrm{kg}$ ). Total flavonols and total polyphenols were the sums of the corresponding compounds, quantified by HPLC. The average degree of polymerization of flavan-3-ols was calculated as the molar ratio of all the flavan-3-ols units (thioether adducts plus 
terminal units) to (-)-epicatechin and (+)-catechin corresponding to terminal units.

\subsection{Antioxidant activity: inhibition of linoleic acid peroxidation}

A freshly prepared $2.55 \mathrm{mM}$ solution of linoleic acid $(2 \mathrm{~mL})$ in a pH 7.4 phosphate buffer with $100 \mathrm{mM}$ of $\mathrm{NaCl}$ containing $10 \mathrm{mM}$ SDS (sodium dodecyl sulfate) were placed at $37^{\circ} \mathrm{C}$ in the spectrometer cell. At time zero, $25 \mu \mathrm{L}$ of a freshly prepared $80 \mathrm{mM}$ solution of AAPH (2,2'-azobis(2-amidinopropane)) in the same buffer was added (Roche et al., 2005). After $15 \mathrm{~min}, 25 \mu \mathrm{L}$ of an antioxidant solution were added in $\mathrm{MeOH}$. The experiments were repeated with different phenol concentrations ( $1 \mathrm{mM}$ and lower). The initial level of hydroperoxides (molar absorption coefficient at $234 \mathrm{~nm}=26$ $100 \mathrm{M}^{-1} \mathrm{~cm}^{-1}$ ) were below $2 \%$ in all experiments. The uninhibited and inhibited peroxidation rates were calculated from the slope of the absorbance at $234 \mathrm{~nm}$ versus time before and after antioxidant addition using fixed time intervals. All experiments were carried out in triplicates. Standard deviations were lower than $10 \%$.

\subsection{Experimental design}

Results of preliminary investigations showed the volume of solvent to be used in the extraction (thus, the solid:liquid ratio)affect the extraction of polyphenols due to an insufficient interaction between the solvent and the matrix. This parameter had an influence on the applied ultrasonic intensity, since a minimum of free liquid is necessary to the functioning of the apparatus. In addition, the temperature and sonication duration have an interaction in the experiment since the ultrasonic energy input tends to increase the temperature of the medium, and both parameters have a direct influence in the yield of extracted polyphenols. Therefore, results of preliminary studies showed polyphenols yield is mainly dependent on the ratio of solvent to sample, the extraction time, the temperature and the ultrasonic intensity.

In order to investigate the influence and relevance of the operating parameters required during extractions, a Central Composite Design (CCD) was used to analyze total polyphenol content (TPC) and extract main polyphenols. Three independent factors (namely temperature $(T)$, sonication duration $(t)$ and Ultrasonic intensity $(U I))$ were evaluated, as well as eventual interaction between these variables.

The full uniformly routable CCD presents the following characteristics (Bezerra et al., 2008): (1) total number of experiments $(N)$ are given $N=k^{2}+2 k+c p$, where $k$ is the number of variables and $c p$ is the number of replicates of the central point; (2) The star points are at a distance $\alpha$ from the center of the design and $\alpha$-values are calculated by $\alpha=2(\mathrm{k}-\mathrm{p}) / 4$; and (3) all factors are studied in five levels $(-\alpha,-1,0,+1,+\alpha)$. Therefore, in the case of three variables, the number of experiences is 20 , the number of replicates of the central point in 6 and the $\alpha$-value is 1.68 .

Preliminary experiments allowed us to distinguish the variables implied in the model at five separated coded levels: $-\alpha(=-1.68)$, $-1,0,+1,+\alpha(=+1.68)$. The limit values of each variable range were chosen as function of limitations of ultrasonic apparatus (minimum and maximum power available in the device), temperature of extraction for polyphenols (which might degrade above $40{ }^{\circ} \mathrm{C}$ ) and time of sonication. Values are presented on Table 1 and involved a total of 20 experiments; including six replications at the centre point to evaluate experimental error measurement, and randomized to avoid effects of extraneous variables. Variables were coded according to the following Eq. (3), where $X_{\mathrm{i}}$ is the coded value, $x_{\mathrm{i}}$, the real value of a variable, $\bar{X}_{i}$, the real value of a variable at the center point, and $\Delta x_{i}$, the step change:
Table 1

Variables involved in the Central Composite Design (CCD)and response obtained for TPC.

\begin{tabular}{lllll}
\hline No & $U I\left(\mathrm{~W} / \mathrm{cm}^{2}\right)^{\mathrm{a}}$ & Temperature $\left({ }^{\circ} \mathrm{C}\right)$ & Sonication time $(\mathrm{min})$ & $\mathrm{TPC}^{\mathrm{b}}$ \\
\hline 1 & 0.431 & 16 & 45 & 370 \\
2 & 0.575 & 10 & 30 & 315 \\
3 & 0.719 & 16 & 45 & 381 \\
4 & 0.719 & 16 & 15 & 306 \\
5 & 0.431 & 16 & 15 & 288 \\
6 & 0.335 & 25 & 30 & 360 \\
7 & 0.575 & 25 & 55 & 384 \\
8 & 0.575 & 25 & 30 & 368 \\
9 & 0.431 & 34 & 45 & 384 \\
10 & 0.575 & 25 & 30 & 393 \\
11 & 0.575 & 25 & 5 & 257 \\
12 & 0.719 & 34 & 15 & 370 \\
13 & 0.719 & 34 & 45 & 448 \\
14 & 0.431 & 34 & 15 & 382 \\
15 & 0.575 & 25 & 30 & 380 \\
16 & 0.575 & 25 & 30 & 383 \\
17 & 0.575 & 25 & 30 & 379 \\
18 & 0.575 & 25 & 30 & 467 \\
19 & 0.575 & 40 & 30 & 393 \\
20 & 0.764 & 25 & 30 & \\
\hline
\end{tabular}

a $U I$ : ultrasonic intensity.

b mg catechin eq/100 g MS.

$X_{i}=\frac{x_{i}-\bar{x}_{i}}{\Delta x_{i}}$

Experimental data for predicting TPC have then been represented using a second order polynomial Eq. (4) as follows:

$Y=\beta_{0}+\sum_{i=1}^{n} \beta_{i} X_{i}+\sum_{i=1}^{n} \beta_{i i} X_{i}^{2}+\sum_{i=1}^{n-1} \sum_{\substack{j=2 \\ j>i}} \beta_{i j} X_{i} X_{j}$,

Where: $Y$ is the response variable TPC ( $\mathrm{mg}$ of catechin equivalent per $100 \mathrm{~g}$ of dried apple pomace sample), $\beta_{0}$ is the average response obtained during replicated experiments of the $\mathrm{CCD}, \beta_{\mathrm{i}} ; \beta_{\mathrm{ii}} ; \beta_{\mathrm{ij}}$ are the linear, quadratic and cross-product effects, respectively, $X_{\mathrm{i}}$ and $X_{\mathrm{j}}$ are the independent coded variables. The results were analyzed using the Statgraphics $\mathrm{XV}^{\circledR}$ software.

\subsection{Kinetics studies}

The extracts obtained were analyzed with a mathematical model derived from Fick's second law (Herodez et al., 2003). The extraction of polyphenols from apple pomace follows first-order kinetics (Spiro and Jago, 1982), which can be represented as follows:

$C_{\mathrm{t}}=C_{\infty}\left(1-e^{-k t}\right)$

Where $C_{\mathrm{t}}$ is the concentration of total polyphenols at time $t, C_{\infty}$ is the final concentration of total polyphenols and $k$ is the apparent first-order rate constant of extraction.

When $\ln \left(C_{\infty} /\left[C_{\infty}-C\right]\right)$ is plotted against time, the points fall on two intersecting straight lines, the first with a relatively steep slope and the second with a relatively shallow one. The points of intersection of $\ln \left(C_{\infty} /\left[C_{\infty}-C\right]\right)$ vs. $t$ plots for the fast and the slow stages are termed transition points.

\section{Results and discussion}

\subsection{Solid-liquid ratio}

To determine the optimum solid/liquid ratio, total polyphenol compounds and the liquid absorbing capacity of the apple pomace were considered, as represented in Fig. 1. From this figure it is 
Table 2

ANOVA for TPC in the CCD.

\begin{tabular}{|c|c|c|c|c|c|}
\hline Source & Sum of squares & $D f$ & Mean squares & $f$-radio & $p$-value \\
\hline UI: ultrasonic intensity & 2966.43 & 1 & 2966.43 & 5.84 & 0.0362 \\
\hline$T:$ temperature & 38446.5 & 1 & 38446.5 & 75.72 & 0.0000 \\
\hline$t$ : sonication time & 33210.4 & 1 & 33210.4 & 65.41 & 0.0000 \\
\hline$U I^{2}$ & 14.83 & 1 & 14.83 & 0.03 & 0.8677 \\
\hline UI.T & 224.084 & 1 & 224.084 & 0.44 & 0.5215 \\
\hline UI.t & 1225.13 & 1 & 1225.13 & 2.41 & 0.1514 \\
\hline$T^{2}$ & 653.003 & 1 & 653.003 & 1.29 & 0.2832 \\
\hline T.t & 1653.12 & 1 & 1653.12 & 3.26 & 0.1013 \\
\hline$t^{2}$ & 11470.2 & 1 & 11470.2 & 22.59 & 0.0008 \\
\hline Total error & 5077.52 & 10 & 507.752 & & \\
\hline Total (corr.) & 95724.2 & 19 & & & \\
\hline
\end{tabular}

$R^{2}=0.947 ; R_{\text {adj }}^{2}$ (adjusted for $\left.D f\right)=0.899$.

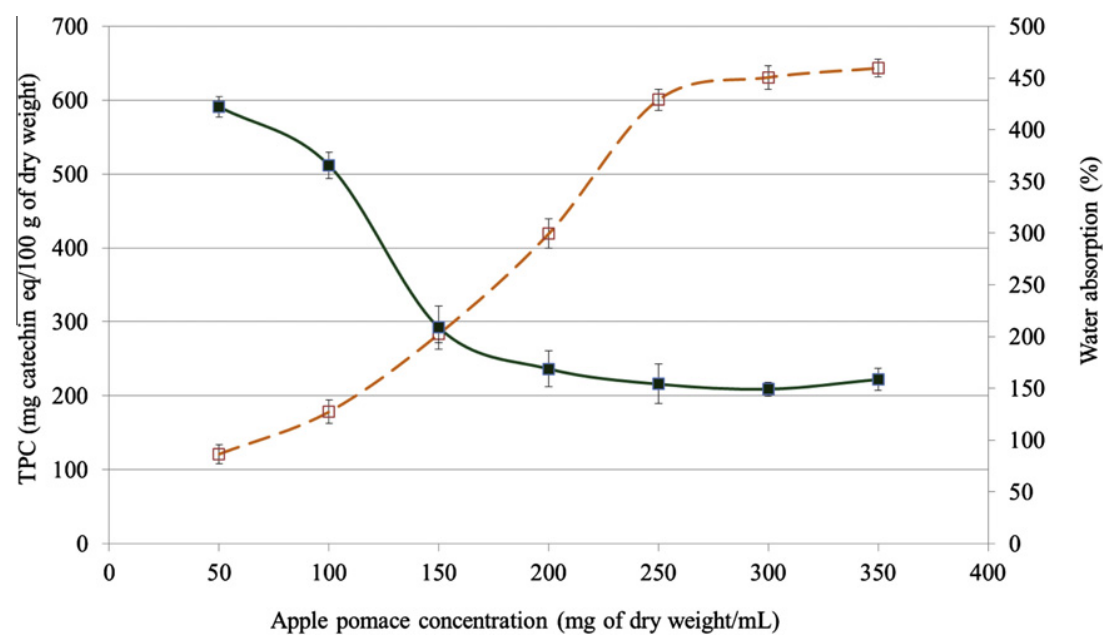

Fig. 1. Optimization of solid/liquid ratio for apple pomace extraction by water: polyphenol concentration in the extract (TPC) ( $\square$ ) and water absorption ( $\square$ ).

possible to observe that the optimum ratio was $150 \mathrm{mg}$ of dry material $/ \mathrm{mL}$. For concentrations above $200 \mathrm{mg} / \mathrm{mL}$ the dry pomace absorbed all of the available liquid, increasing in volume. Since the ultrasound apparatus requires a minimum amount of free solvent for extraction procedures, a combination of high TPC yields and higher amount of available solvent was chosen. The $150 \mathrm{mg} / \mathrm{mL}$ ratio results are corroborated by the values achieved by earlier studies such as Virot et al. (2010) who used ethanol as extraction solvent of dry apple pomace.

\subsection{Experimental design studies}

Three key variables that affect extraction of phenolic compounds were studied in a central composite design: namely, ultrasonic intensity, temperature and sonication duration. Ultrasonic intensity ranged from 0.335 to $0.764 \mathrm{~W} / \mathrm{cm}^{2}$. The chosen ultrasonic intensity limits were function of regulation limitations in the ultrasonic apparatus. Since appropriate temperature setting is necessary to avoid destruction of organic compounds as well as provide an efficient application of ultrasound (ultrasound effects are known to decrease with temperatures higher than $40-50{ }^{\circ} \mathrm{C}$ ), moderate temperatures were chosen with a range of $9.9-40^{\circ} \mathrm{C}$. Also, the increase in cavitation phenomena is directly proportional to the increase in the system temperature. However, at too high temperatures a decrease in shock waves is observed, diminishing the effect of ultrasounds (Lorimer and Mason, 1987). At last, polyphenols might undergo degradation at temperatures higher than $40^{\circ} \mathrm{C}$, especially when combined to ultrasounds (Kyi et al., 2005;
Svitelska et al., 2004); therefore, a maximum temperature of $40{ }^{\circ} \mathrm{C}$ was chosen. Finally, the sonication time range chosen (from 5 to $55 \mathrm{~min}$ ) was relatively short yet competitive with conventional extraction, showing a potential future industrial application. Since after a certain time cavitation bubbles do not continue to absorb energy to grow and collapse (Ozcan, 2006), and the usual time used for ultrasound-assisted extraction in the industry are usually not longer than $60 \mathrm{~min}$ (Chemat et al., 2011), 55 min was chosen as maximum limit. These three controlled variables were studied in a multivariate study with 20 experiments as shown in the Table 1 .

\subsubsection{Results for TPC}

Coded experiments and responses obtained for each run of the central composite design are presented on Table 2 . The responses varied widely in function of parameters settings of experiments (from 257 to $460 \mathrm{mg}$ of catechin equivalent per $100 \mathrm{~g}$ of dry weight). Significance and suitability of the design were then studied using a variance analysis (ANOVA, Table 2). Statistical significance of each effect (including interaction terms, linear and quadratic $\mathrm{T}^{2}$ effects) was tested by comparing the mean square against an estimate of the experimental error. Depending upon the degree of freedom (Df.) involved, F-ratio can be calculated (ratio of the mean squared error to the pure error). With a confidence level of 95\%, F-ratio significance can be evaluated using the $p$-value column (significant effects have been typed in bold). Four effects were found significant at a 95\% confidence level in the experimental domain studied. This observation can also be pointed out on a Pareto chart of standardized effects, presented 


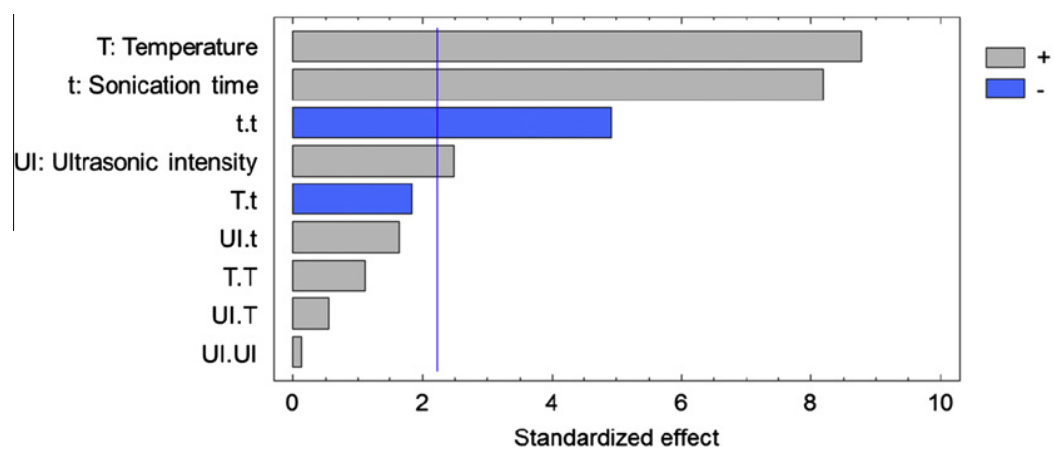

Fig. 2. Standardized Pareto chart of optimization multivariate study.

on Fig. 2. Linear effects of the three key variables $(U I, T, t)$ appear to be highly significant, as well as the quadratic effect of the sonication time $\left(t^{2}\right)$.

The lack of significance of the cross-product terms (UI.T, UI.t, T.t) suggests the absence of interactions between variables. The experimental data obtained from the CCD allowed us to determine an empirical relationship linking response studied (TPC) and key variables involved in the model (in coded units). Thus, a second order polynomial equation was obtained:

$Y=154.0+0.98 \quad U I+5.98 T+10.99 t-0.12 t^{2}$

Where, $Y$ represents TPC (expressed in mg of catechin equivalent per $100 \mathrm{~g}$ of dry weight), UI represents the applied ultrasonic intensity, $t$ is the sonication time and $T$, the temperature in coded units. Only significant variables were shown $(p<0.05)$.The applied model appears to be adequate for our experimental results at the $95 \%$ confidence level. More than $94 \%$ of the variability of responses was explained $\left(R^{2}\right.$ statistics $\left.>0.94\right)$, asserting a good accuracy and ability of the established model within the limits of the range used (Mirhosseini et al., 2008). $R^{2}$ adj is a regression coefficient adjusted for the number of coefficient involved in the model; it allows comparison between models with different numbers of independent variables and allows testing the level of suitability to the regression coefficient. Its value $(>0.89)$ indicates a high degree of correlation between observed and predicted data.

\subsubsection{Optimization of ultrasound-assisted extraction}

A graphical representation can be introduced in order to visualize the significant relationship linking levels of variables and response studied (TPC). Fig. 3 depicts three-dimensional plots, each plot highlighting the response behavior function of two variables with the third variable fixed to its central point. The most influential variables are the linear terms of sonication duration $(t)$ and temperature $(T)$ : TPC increases linearly as sonication time and temperature increase. The same effect has been noticed with ultrasonic intensity (UI) but with a less predominant influence as observed in the Pareto chart. A slight influence of quadratic effect of sonication time $\left(t^{2}\right)$ is also illustrated on these surfaces (presence of weak surface curvature when sonication time increases), Fig. 3a and c optimal settings for TPC maximization were $0.764 \mathrm{~W} / \mathrm{cm}^{2}$ for ultrasonic intensity, $40^{\circ} \mathrm{C}$ for temperature and $40 \mathrm{~min}$ for sonication duration. The TPC yield (555 mg of catechin equivalent per $100 \mathrm{~g}$ of dry weight) predicted by the model was verified experimentally using the optimized settings. Similar results were obtained by Virot et al. (2010) for ultrasound-assisted extraction optimization using ethanol $50 \%\left(0.142 \mathrm{~W} / \mathrm{g}, 40^{\circ} \mathrm{C}\right.$ and $\left.45 \mathrm{~min}\right)$, while other techniques like pressurized fluid extraction and manual maceration resulted in optimized conditions of ethanol $60 \%$ and $102{ }^{\circ} \mathrm{C}$ (Wijngaard and Brunton, 2009) and ethanol $56 \%$ at $80^{\circ} \mathrm{C}$ for $31 \mathrm{~min}$ or acetone $65 \%$ at $25^{\circ} \mathrm{C}$ for $60 \mathrm{~min}$ (Wijngaard and Brunton,
2010), respectively. This shows the importance of optimizing parameters when a modification is done in one or various parameters such as solid/liquid ratio, temperature or solvent. Our extracts were obtained and optimized for water extraction, showing the viability of this procedure with great yields using water as solvent.
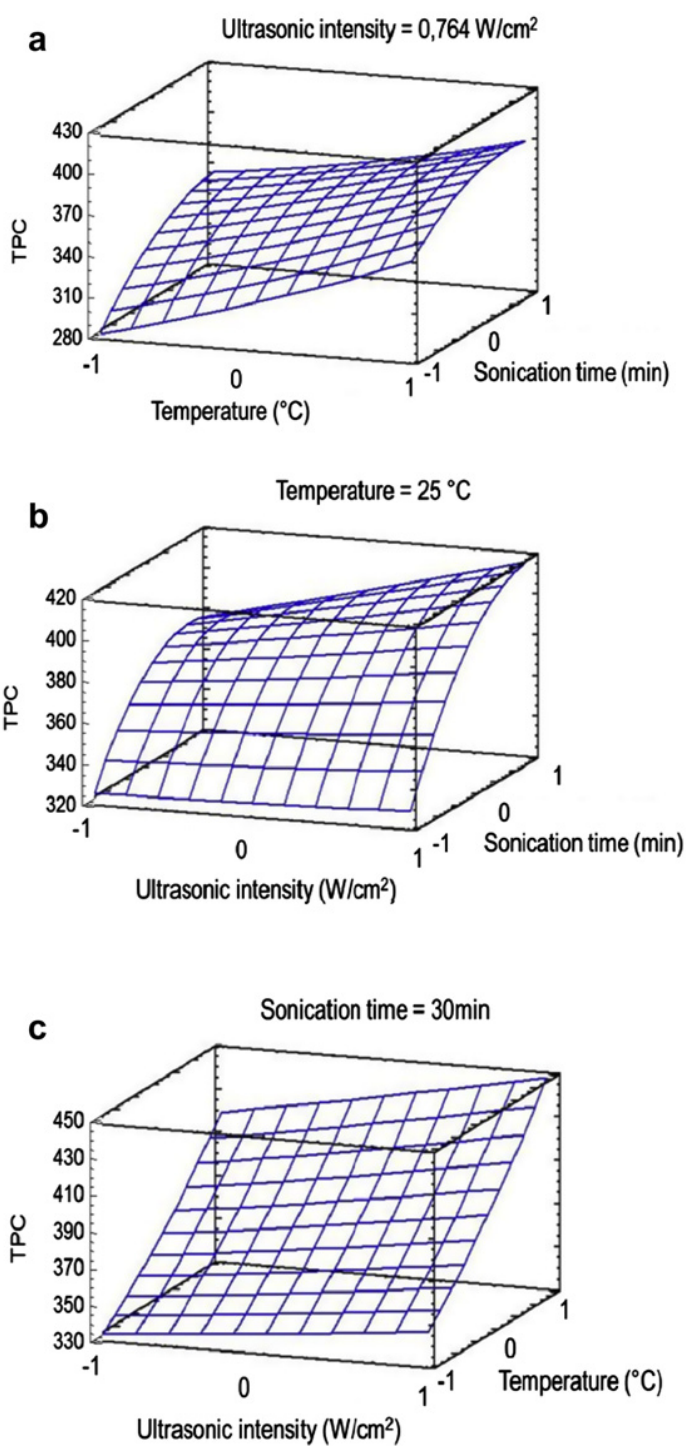

Fig. 3. Optimization of ultrasound-assisted apple pomace extraction by water: TPC investigation in the multivariate study: (A) TPC as a function of ultrasonic intensity and sonication time, (b) TPC as a function of ultrasonic intensity and temperature, and (c) TPC as a function of temperature and sonication time. 


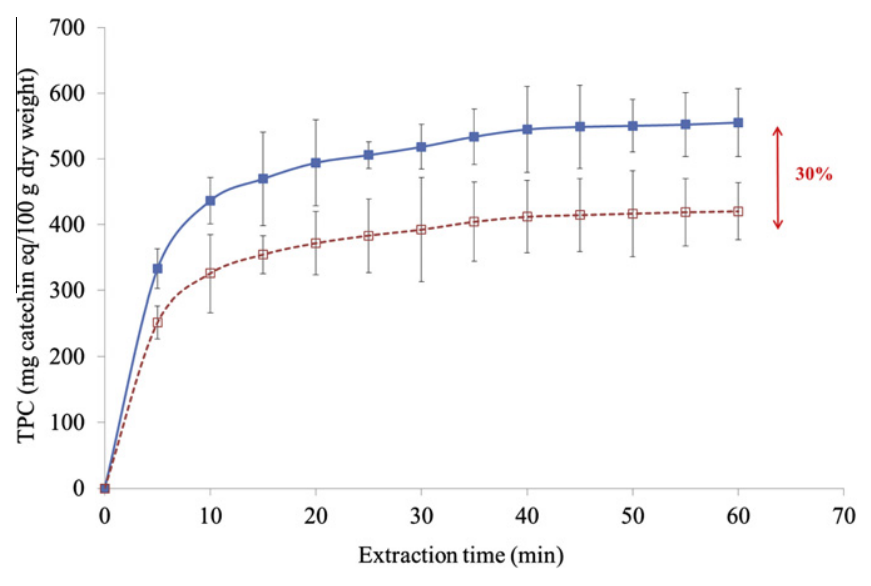

Fig. 4. Comparison between conventional (CE- $\square$ ) and ultrasound-assisted extraction(US- $\mathbf{0})$.

\subsection{Comparison and kinetic studies}

To evaluate the impact of ultrasound-assisted extraction in optimized conditions obtained from the response surface method, a comparison study was carried out between ultrasound and conventional extractions (Fig. 4; Table 3). From Fig. 4, it is possible to observe that ultrasound-assisted extraction increased in TPC yield by more than $30 \%$ ( 420 and $555 \mathrm{mg}$ of catechin equivalent per $100 \mathrm{~g}$ of dry weight for conventional and ultrasound-assisted extraction, respectively). The comparison shows a clear improvement of the extraction, which is attributed to ultrasonic cavitation, since this is the only variable of treatment that differs in both experiments.

From the Table 3 it is possible to observe that extracts are rich in catechin monomers and phenolic acids, while residues are poor in phenolic acids and rich in procyanidins with a slight increase of the respective DP, which might be attributed to interactions between those compounds and the plant cell wall since the greater the DP, stronger the interaction (Le Bourvellec et al., 2007).
The ultrasound extracts are richer in phenolic acids than the conventional extracts, mainly for PCQ. Also, monomers were better extracted than polymers, which was expected since the extraction was performed in an aqueous medium. In the case of the dihydrochalcones, since they are more present in the seeds, the grinding has a lot of influence. In our work, no grinding was used, which explains the greater amount in the residue compared to the extracts. Flavonols were not well extracted, which could be solved by a pre-treatment of apple peels. Phloridzine was not well recovered, probably due to its polarity, even though dihydrochalcones were better extracted by ultrasounds than by the conventional technique. Yields on ultrasound assisted extraction are greater for catechin, epicatechin and flavonols, which implies a partial destructuring of the apple epidermis, suggesting a not full destructuring of apple epidermis by ultrasounds in this naturally resistant fraction. As for flavonols, yields are variable, possibly due to their solubility in the buffer. Ultrasounds increase extract yield in $6-8 \%$ for dihydrochalcones and phenolic acids, although results suggest the bonds between polyphenols and polysaccharides were not broken, since polyphenols present a strong interaction with apple cell walls (Le Bourvellec et al., 2004; Le Bourvellec and Renard, 2005; Le Bourvellec et al., 2009). This amount of retention of polyphenols has already been observed in the literature (Kołodziejczyk et al., 2009).

Both extractions (conventional and optimized) follow first-order kinetics, with a fast period from 0 to $10 \mathrm{~min}$ and a slow period from 10 to $40 \mathrm{~min}$ of extraction as represented in the Fig. 5 together with their respective coefficients. Indeed, the coefficients at the fast period are of $0.162 \mathrm{~min}^{-1}$ for the ultrasound and $0.158 \mathrm{~min}^{-1}$ for the conventional extraction; while for the slow period, the coefficients are of $0.088 \mathrm{~min}^{-1}$ for the ultrasound and of $0.085 \mathrm{~min}^{-1}$ for the conventional extraction. Since the difference between the coefficients for both equations were not significant, it is possible to conclude that the ultrasound treatment did not change the kinetics of the extraction, even though the extract yield for the ultrasound treatment is more important, which can be explained by the cavitation phenomena.

Some studies on the effects of ultrasound-assisted extraction using electronic microscopy (Veillet et al., 2010)showed that the cavitation phenomena is responsible for modifications on the plant

Table 3

Yields and polyphenol composition of apple pomace and its water extracts obtained by conventional and ultrasound-assisted optimized extraction. Yields are in \% dry matter, and polyphenol composition in $\mathrm{mg} / \mathrm{kg}$ of dry weight. The values in italics are the yields recorded for individual components.

\begin{tabular}{|c|c|c|c|c|c|c|c|c|c|c|c|c|c|c|c|c|c|c|}
\hline & \multirow{3}{*}{$\begin{array}{l}\text { Yields (g/g } \\
\text { DW) }\end{array}$} & \multicolumn{4}{|c|}{ Flavans-3-ols } & \multicolumn{2}{|c|}{ Dihydrochalcones } & \multicolumn{2}{|c|}{$\begin{array}{l}\text { Phenolic } \\
\text { acids }\end{array}$} & \multicolumn{8}{|c|}{ Flavonols } & \multirow[t]{3}{*}{ TPC } \\
\hline & & \multicolumn{2}{|c|}{$\underline{\text { Monomers }}$} & \multicolumn{2}{|l|}{ PCA } & \multirow[t]{2}{*}{ XPL } & \multirow[t]{2}{*}{ PLZ } & \multirow[t]{2}{*}{ CQA } & \multirow[t]{2}{*}{$\mathrm{pCA}$} & \multirow[t]{2}{*}{ Rut } & \multirow[t]{2}{*}{ Hyp } & \multirow[t]{2}{*}{ Iso } & \multirow[t]{2}{*}{ Rey } & \multirow[t]{2}{*}{ Gua } & \multirow[t]{2}{*}{ Avi } & \multirow[t]{2}{*}{ Qc } & \multirow[t]{2}{*}{ SUM } & \\
\hline & & CAT & $\mathrm{EC}$ & PCA & DP & & & & & & & & & & & & & \\
\hline Initial Pomace & 1.00 & 52 & 244 & 3408 & 3.6 & 142 & 1008 & 960 & 94 & 10 & 122 & 42 & 54 & 161 & 24 & 40 & 453 & 6360 \\
\hline $\begin{array}{l}\text { Conventional } \\
\text { extract }\end{array}$ & 0.27 & 114 & 383 & 1249 & 3.1 & 180 & 1014 & 1321 & 133 & 22 & 150 & 52 & 56 & 169 & 24 & 38 & 511 & 4905 \\
\hline $\begin{array}{l}\text { Conventional } \\
\text { residue }\end{array}$ & 0.70 & 37 & 193 & 4132 & 4.4 & 103 & 928 & 545 & 50 & 10 & 147 & 47 & 66 & 201 & 32 & 45 & 549 & 6537 \\
\hline Optimized extract & 0.28 & 153 & 477 & 1335 & 4.0 & 199 & 1093 & 1399 & 141 & 27 & 211 & 71 & 80 & 242 & 35 & 53 & 721 & 5517 \\
\hline Optimized residue & 0.69 & 40 & 197 & 4304 & 4.7 & 108 & 1050 & 602 & 52 & 10 & 157 & 49 & 69 & 205 & 33 & 47 & 570 & 6923 \\
\hline pSTD & & 30 & 88 & 283 & 0.6 & 14 & 91 & 99 & 10 & 4 & 30 & 10 & 11 & 31 & 4 & 6 & 97 & 360 \\
\hline Initial Pomace & & 1.00 & 1.00 & 1.00 & & 1.00 & 1.00 & 1.00 & 1.00 & 1.00 & 1.00 & 1.00 & 1.00 & 1.00 & 1.00 & 1.00 & 1.00 & 1.00 \\
\hline $\begin{array}{l}\text { Conventional } \\
\text { extract }\end{array}$ & & 0.59 & 0.42 & 0.10 & & 0.34 & 0.27 & 0.37 & 0.38 & 0.63 & 0.33 & 0.34 & 0.28 & 0.28 & 0.26 & 0.25 & 0.30 & 0.21 \\
\hline $\begin{array}{l}\text { Conventional } \\
\text { residue }\end{array}$ & & 0.50 & 0.55 & 0.85 & & 0.51 & 0.64 & 0.40 & 0.38 & 0.74 & 0.85 & 0.78 & 0.85 & 0.87 & 0.93 & 0.79 & 0.85 & 0.72 \\
\hline Optimized extract & & 0.83 & 0.55 & 0.11 & & 0.39 & 0.30 & 0.41 & 0.42 & 0.80 & 0.49 & 0.48 & 0.41 & 0.42 & 0.40 & 0.37 & 0.45 & 0.24 \\
\hline Optimized residue & & 0.53 & 0.56 & 0.87 & & 0.53 & 0.72 & 0.43 & 0.39 & 0.76 & 0.89 & 0.81 & 0.88 & 0.88 & 0.92 & 0.80 & 0.87 & 0.75 \\
\hline
\end{tabular}

CAT: (+)-catechin; EC: (-)-epicatechin; PCA: procyanidins; DP: number average degree of polymerisation; XPL: phloretinxyloglucoside; PLZ: phloridzin; CQA: 5'caffeoylquininc acid (chlorogenic acid); pCA: paracoumaroylquinic acid; Rut: rutin (quercetin-3-O-rutinoside); Hyp: Hyperoside (quercetin 3-O-galactoside); Iso: Isoquercitrin (quercetin 3-O-glucoside); Rey: reynoutrine (quercetin 3-O-xyloside); Gua: guajaverin((quercetin 3-O-arabinopyranoside); Avi:avicularin (quercetin 3-O-arabinoside); Qc: quercitrin (quercetin 3-O-rhamnoside);pSTD: pooled standard deviations. 


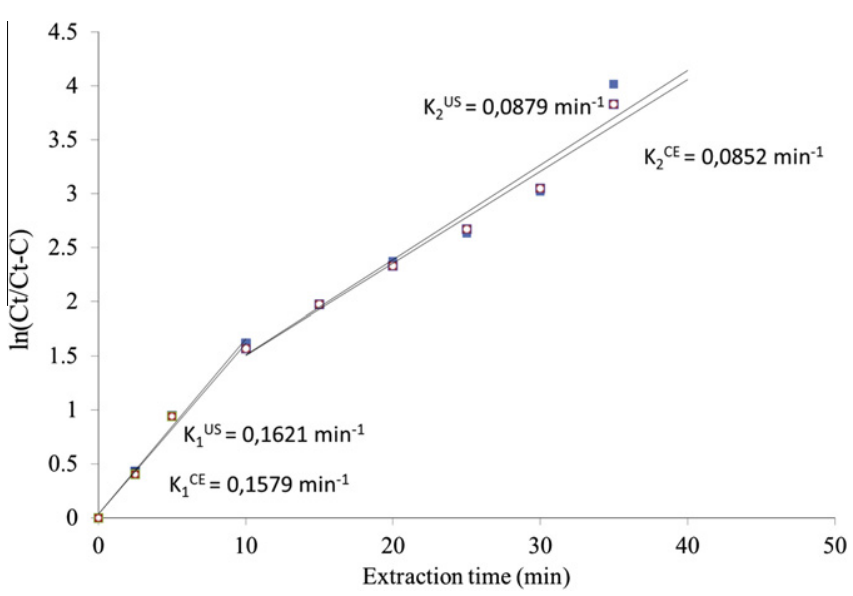

Fig. 5. Kinetics and respective constants for conventional (CE- $\square$ ) and ultrasoundassisted extraction (US-ם).
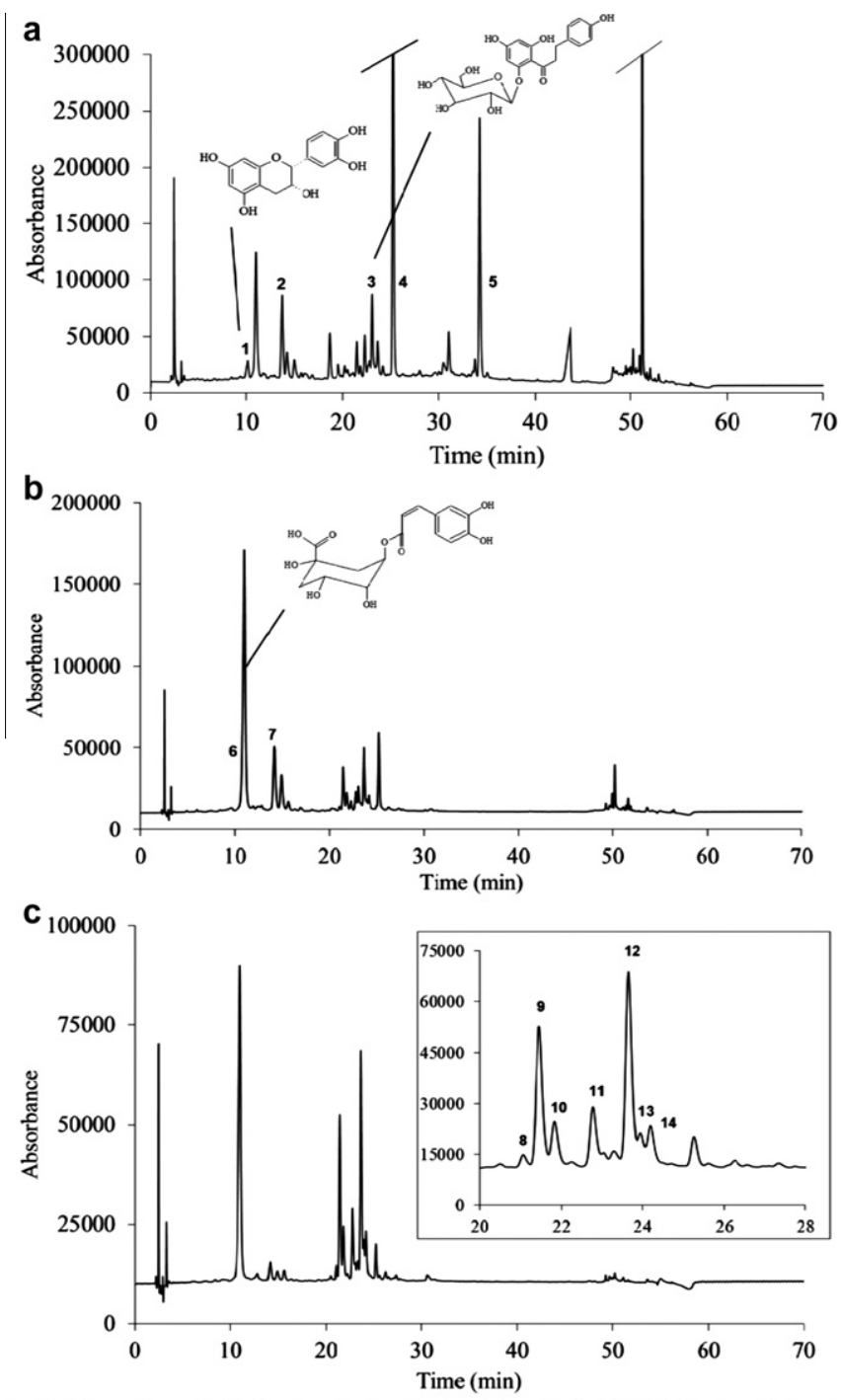

A: Abs $280 \mathrm{~nm}$ : (+)-catechin (1), (-)-epicatechin (2), phloretin xyloglucoside (3), phloridzin (4), epicatechin benzyl thioether (5); B: Abs $325 \mathrm{~nm}$ : 5'-caffeoylquinic acid (chlorogenic acid) (6), p-coumarinic acid (7); C: Abs $350 \mathrm{~nm}$ rutin (8), hyperoside (9), isoquercetin (10), renoutrin (11), guajaverin (12), avicularin (13), quercitrin (14).

Fig. 6. C18 reverse phase HPLC-DAD chromatograms of ultrasound-assisted extracted apple pomace polyphenols at A: $280 \mathrm{~nm}$; B: $320 \mathrm{~nm}$; C: $350 \mathrm{~nm}$. material inducing disruption of the cells, due to the burst of the cavitation bubble on the surface of the matrix (Vinatoru, 2001). Studies can be done directly in the cell wall to verify the state before and after extraction, nevertheless due to the heterogeneity and complexity of our matrix (apple pomace), cytological or histological studies of these samples would not provide reliable statistical results.

\subsection{Antioxidant activity}

The antioxidant activity was evaluated for both conventional and ultrasound-assisted extraction carried out in the optimized conditions. The experiments were monitored by UV/VIS spectroscopy by recording the accumulation of the lipid hydroperoxides $\left(\lambda_{\max }=234 \mathrm{~nm}\right)$ in the absence of antioxidant (constant peroxidation rate $R \mathrm{p}^{0}$ ) and in the presence of the antioxidant (initial peroxidation rate $R \mathrm{p}$ ). The $\mathrm{IC}_{50}$ parameters (antioxidant concentration corresponding to $50 \%$ inhibition, i.e. $\left.R \mathrm{p} / R \mathrm{p}^{0}=0.5\right)$ were calculated for both samples. Sonicated extracts present a lower $\mathrm{IC}_{50}$ $(4.90 \mu \mathrm{M})$, representing a better antioxidant activity for those samples when compared to the activity of extracts obtained from maceration $(7.05 \mu \mathrm{M})$. Quercetin presented an $\mathrm{IC}_{50}$ value of $0.58 \mu \mathrm{M}$.

\subsection{Ultrasound effects on extracted molecules}

In order to verify the innocuousness of ultrasound, three isolated compounds of apple pomace (namely (-)epicatechin, phloridzin and chlorogenic acid)were submitted to the optimized ultrasound extraction conditions. The degradation of these isolated products was evaluated comparing the initial mass to quantified final mass after treatment using HPLC-DAD (Fig. 6) against standards. These compounds were chosen due to their high concentration in the apple and/or importance of application, like phloridzin, which is mainly present in the apple fruit. We observed no specific reaction products after ultrasound treatment. For chlorogenic acid $97.6 \%$ of the initial mass was quantified after US treatment, against $94.7 \%$ for epicatechin and $99.2 \%$ for phloridzin. This loss of $5 \%$ in weight can be due to experimental error.

\subsection{Large scale ultrasound extraction}

While conventional procedures such as maceration are often time and/or energy consuming, ultrasound-assisted extraction provides numerous advantages from an industrial perspective. Ultrasound as a food processing technology has shown large commercial large scale application, with high returns on capital investment (with the break-even point about 4 months). Improvements in product efficiency, process enhancement and low maintenance cost are achievable on a commercial scale. Also, depending on the application, the required energy is comparable to other operation units currently utilized in the industry (Patist and Bates, 2008; Paniwnyk et al., 2009). Only $40 \mathrm{~min}$ in water (a green environmental solvent) are needed to recover polyphenols from apple pomace with higher yields compared to conventional extraction procedures. The recycling of an industrial byproduct such as apple pomace using a rapid technique consuming less energy is advantageous from an environmental point of view. For this purpose, a pilot study was performed in a $30 \mathrm{~L}$ extraction tank (Fig. 7)consisting of a quadruple output of ultrasound at $25 \mathrm{kHz}$ and $4 \times 200$ Watts in the optimum conditions obtained from the previous experiments. Polyphenol yields in the ultrasound extraction were comparable to the lab scale experiments and 15\% higher when compared to the conventional procedure using maceration $(560 \mathrm{mg}$ catechin equivalent per $100 \mathrm{~g}$ of dry weight for sonicated samples against 


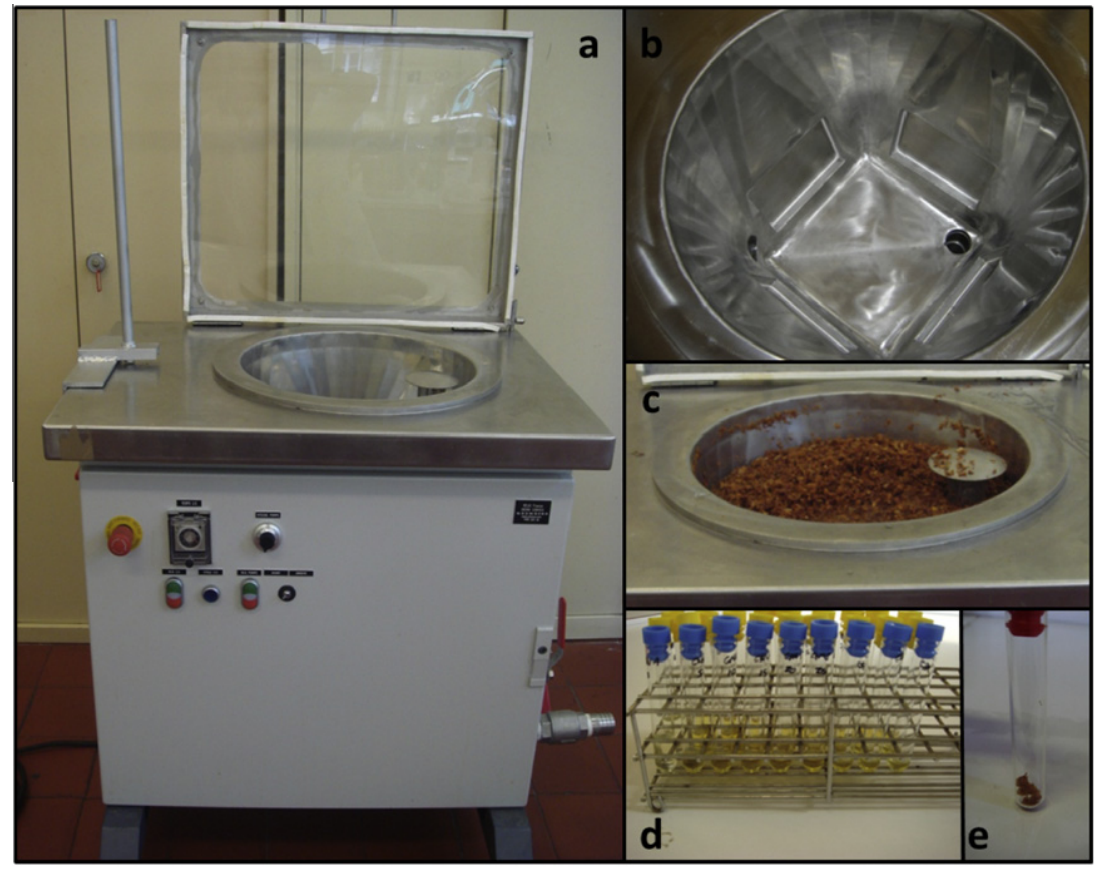

Large scale ultrasound apparatus (a), inside view of apparatus (b), UAE of apple pomace (c), liquid extract (d), and lyophilized extract (e).

Fig. 7. Large scale ultrasound-assisted extraction.

$487 \mathrm{mg}$ catechin equivalent per $100 \mathrm{~g}$ of dry weight for conventional ones).

\section{Conclusion}

When compared to conventional maceration extraction, optimized ultrasonic treatment showed an increase of more than 30\% in total phenolic content after $40 \mathrm{~min}$, which was confirmed by large scale experiments, showing the potential applicability of the technique in industries. At the same time, the HPLC-DAD data clearly showed that there was no modification or degradation of the extract and its composition regarding the polyphenolic species.

\section{Acknowledgements}

This work was funded by Agence Nationale de la Recherche within Project ANR-07-PNRA-030TEMPANTIOX "New processes for production of fruit derived products with optimized organoleptic and nutritional qualities".

\section{References}

Akiyama, H., Sakushima, J.-ichi, Taniuchi, S., Kanda, T., Yanagida, A., Kojima, T. Teshima, R., Kobayashi, Y., Goda, Y., Toyoda, M., 2000. Antiallergic effect of apple polyphenols on the allergic model mouse. Biological \& Pharmaceutical Bulletin 23, 1370-1373.

Barbero, G., Liazid, A., Palma, M., Barroso, C., 2008. Ultrasound-assisted extraction of capsaicinoids from peppers. Talanta 75 (5), 1332-1337.

Bezerra, M.A., Santelli, R.E., Oliveira, E.P., Villar, L.S., Escaleira, L.A., 2008. Response surface methodology (RSM) as a tool for optimization in analytical chemistry. Talanta 76, 965-977.

Caldeira, I., Pereira, R., Clímaco, M.C., Belchior, A.P., Bruno de Sousa, R., 2004 Improved method for extraction of aroma compounds in aged brandies and aqueous alcoholic wood extracts using ultrasound. Analytica Chimica Acta 513 (1), 125-134.

Cao, X., Wang, C., Pei, H., Sun, B., 2009. Separation and identification of polyphenols in apple pomace by high-speed counter-current chromatography and highperformance liquid chromatography coupled with mass spectrometry. Journal of Chromatography A 1216 (19), 4268-4274.
Cetkovic, G., Canadanovicbrunet, J., Djilas, S., Savatovic, S., Mandic, A., Tumbas, V., 2008. Assessment of polyphenolic content and in vitro antiradical characteristics of apple pomace. Food Chemistry 109 (2), 340-347.

Chemat, F., Zill-e-Huma, Khan, M.K., 2011. Applications of ultrasound in food technology: processing, preservation and extraction. Ultrasonics Sonochemistry 18 (4), 813-835.

Chen, F., Sun, Y., Zhao, G., Liao, X., Hu, X., Wu, J., Wang, Z., 2007. Optimization of ultrasound-assisted extraction of anthocyanins in red raspberries and identification of anthocyanins in extract using high-performance liquid chromatography-mass spectrometry. Ultrasonics Sonochemistry 14 (6), 767-778.

Guyot, S., Marnet, N., Drilleau, J., 2001. Thiolysis-HPLC characterization of apple procyanidins covering a large range of polymerization states. Journal of Agricultural and Food Chemistry 49 (1), 14-20.

Guyot, S., Marnet, N., Laraba, D., Sanoner, P., Drilleau, J., 1998. Reversed-Phase HPLC following thiolysis for quantitative estimation and characterization of the four main classes of phenolic compounds in different tissue zones of a French cider apple variety (Malus domestica Var. Kermerrien). Journal of Agricultural and Food Chemistry 46 (5), 1698-1705.

Guyot, S., Marnet, N., Sanoner, P., Drilleau, J., 2003. Variability of the polyphenolic composition of cider apple (Malus domestica) fruits and juices. Journal of Agricultural and Food Chemistry 51 (21), 6240-6247.

Herodez, S.S., Hadolin, M. Skerget, M., Knez, Z, 2003. Solvent extraction study of antioxidants from Balm (Melissa officinalis L.) leaves. Food Chemistry 80 (2), 275-282.

Hilt, P., Schieber, A., Yildirim, C., Arnold, G., Klaiber, I., Conrad, J., Beifuss, U., Carle, R., 2003. Detection of phloridzin in strawberries (Fragaria $\times$ ananassa Duch.) by HPLC-PDA-MS/MS and NMR spectroscopy. Journal of Agricultural and Food Chemistry 51 (10), 2896-2899.

Kanda, T., Akiyama, H., Yanagida, A., Tanabe, M., Goda, Y., Toyoda, M., Teshima, R., Saito, Y., 1998. Inhibitory effects of apple polyphenol on induced histamine release from RBL-2H3 cells and rat mast cells. Bioscience, Biotechnology, and Biochemistry 62 (7), 1284-1289.

Khan, M.K., Abert-Vian, M., Fabiano-Tixier, A.S., Dangles, O., Chemat, F., 2010 Ultrasound-assisted extraction of polyphenols (flavanone glycosides) from orange (Citrus sinensis L.) peel. Food Chemistry.

Kołodziejczyk, K., Kosmala, M., Milala, J., Sójka, M., Uczciwek, M., Król, B. Markowski, J., Renard, C.M.G.C., 2009. Characterisation of the chemical composition of scab-resistant apple pomaces. Journal of Horticultural Science and Biotechnology 84, 89-95.

Kyi, T.M., Daud, W.R.W., Mohammad, A.B., Wahid Samsudin, M., 2005. The kinetics of polyphenol degradation during the drying of Malaysian cocoa beans. International Journal of Food Science and Technology 40, 323-331.

Le Bourvellec, C., Guyot, S., Renard, C.M.G.C., 2004. Non-covalent interaction between procyanidins and apple cell wall material Part 1: effect of some environmental parameters. Biochim. Biophys. Acta 1672, 192-202.

Le Bourvellec, C. Renard, C.M.G.C. 2005. Non-covalent interactions between procyanidins and apple cell wall material. Part II: quantification and impact of cell wall drying. Biochim. Biophys. Acta 1675, 1-9. 
Le Bourvellec, C., Le Quere, J.-M., Renard, C.M.G.C., 2007. Impact of noncovalent interactions between apple condensed tannins and cell walls on their transfer from fruit to juice. Studies in model suspensions and application. Journal of Agricultural and Food Chemistry 55 (19), 7896-7904.

Lebourvellec, C., Guyot, S., Renard, C., 2009. Interactions between apple (Malus $\times$ domestica Borkh.) polyphenols and cell walls modulate the extractability of polysaccharides. Carbohydrate Polymers 75 (2), 251-261.

Lorimer, J.P., Mason, T.J., 1987. Sonochemistry. Part 1-The physical aspects. Chemical Society Reviews 16, 239.

Lu, Y., 2000. Antioxidant and radical scavenging activities of polyphenols from apple pomace. Food Chemistry 68 (1), 81-85.

Lu, Y., Foo, Y., 1997. Identification and quantification of major polyphenols in apple pomace. Food Chemistry 59 (2), 187-194.

Ma, Y., Chen, J., Liu, D., Ye, X., 2009. Simultaneous extraction of phenolic compounds of citrus peel extracts: effect of ultrasound. Ultrasonics Sonochemistry 16 (1), $57-62$.

Mangas, J.J., Rodriguez, R., Suarez, B., Picinelli, A., Dapena, E., 1999. Study of the phenolic profile of cider apple cultivars at maturity by multivariate techniques. Journal of Agricultural and Food Chemistry 47 (10), 4046-4052.

Mirhosseini, H., Tan, C.P., Hamid, N.S., Yusof, S., 2008. Effect of Arabic gum, xanthan gum and orange oil on flavor release from diluted orange beverage emulsion. Food Chemistry 107 (3), 1161-1172.

Ozcan, E., 2006. Ultrasound assisted extraction of phenolics from grape pomace. Middle East Technical University, The graduate School of Natural and Applied Sciences, Ph.d., Chemical Engineering, Ankara.

Paniwnyk, L., Cai, H., Albu, S., Mason, T., Cole, R., 2009. The enhancement and scale up of the extraction of anti-oxidants from Rosmarinus officinalis using ultrasound. Ultrasonics Sonochemistry 16 (2), 287-292.

Patist, A., Bates, D., 2008. Ultrasonic innovations in the food industry: from the laboratory to commercial production. Innovative Food Science \& Emerging Technologies 9 (2), 147-154.

Price, K., 1999. A comparison of the flavonol content and composition in dessert, cooking and cider-making apples; distribution within the fruit and effect of juicing. Food Chemistry 66 (4), 489-494.

Roche, M., Dufour, C., Mora, N., Dangles, O., 2005. Antioxidant activity of olive phenols: mechanistic investigation and characterization of oxidation products by mass spectrometry. Organic \& Biomolecular Chemistry 3 (3), 423.

Rodrigues, S., Pinto, G.A., Fernandes, F.A., 2008. Optimization of ultrasound extraction of phenolic compounds from coconut (Cocos nucifera) shell powder by response surface methodology. Ultrasonics Sonochemistry 15 (1), 95-100.

Sanoner, P., Guyot, S., Marnet, N., Molle, D., Drilleau, J.-F., 1999. Polyphenol profiles of French cider apple varieties (Malus domestica sp.). Journal of Agricultural and Food Chemistry 47 (12), 4847-4853.

Shoji, T., Akazome, Y., Kanda, T., Ikeda, M., 2004. The toxicology and safety of apple polyphenol extract. Food and Chemical Toxicology 42 (6), 959-967.

Shoji, T., Kobori, M., Shinmoto, H., Yanagida, A., Kanda, T., Tsushida, T., 2000. Inhibitory effects of apple polyphenols on differentiation of 3T3-L1 cells into adipocytes. Food Science and Technology Research 6 (2), 119-121.
Singleton, V.L., Rossi, J.A., 1965. Colorimetry of total phenolics with phosphomolybdic-phosphotungstic acid reagents. American Journal of Enology Viticulture 16 (3), 144-158.

Spiro, M., Jago, D.S., 1982. Kinetics and equilibria of tea infusion. Part 3. -Rotatingdisc experiments interpreted by a steady-state model. Journal of the Chemical Society, Faraday Transactions 178 (1), 295-305.

Suárez, B., Álvarez, Á.L., García, Y.D., Barrio, G.D., Lobo, A.P., Parra, F., 2010. Phenolic profiles, antioxidant activity and in vitro antiviral properties of apple pomace. Food Chemistry 120 (1), 339-342.

Svitelska, G., Gallios, G., et Zouboulis, A., 2004. Sonochemical decomposition of natural polyphenolic compound (condensed tannin). Chemosphere 56 (10), 981-987.

Tiwari, B.K., Muthukumarappan, K., O’Donnell, C.P., Cullen, P.J., 2008. Effects of sonication on the kinetics of orange juice quality parameters. Journal of Agricultural and Food Chemistry 56 (7), 2423-2428.

Toma, M., Fukutomi, S., Asakura, Y., Koda, S. 2011. A calorimetric study of energy conversion efficiency of a sonochemical reactor at $500 \mathrm{kHz}$ for organic solvents. Ultrasonics Sonochemistry 18 (1), 197-208.

Van der Sluis, A.A., Dekker, M., Skrede, G., Jongen, W.M.F., 2002. Activity and concentration of polyphenolic antioxidants in apple juice. 1. effect of existing production methods. Journal of Agricultural and Food Chemistry 50 (25), 72117219.

Veillet, S., Tomao, V., Chemat, F., 2010. Ultrasound assisted maceration: An original procedure for direct aromatisation of olive oil with basil. Food Chemistry 123 (3), 905-911.

Vinatoru, M., 2001. An overview of the ultrasonically assisted extraction of bioactive principles from herbs. Ultrasonics Sonochemistry 8 (3), 303-313.

Virot, M., Tomao, V., Le Bourvellec, C., Renard, C.M., Chemat, F., 2010. Towards the industrial production of antioxidants from food processing by-products with ultrasound-assisted extraction. Ultrasonics Sonochemistry 17 (6), 1066-1074.

Wang, J., Sun, B., Cao, Y., Tian, Y., Li, X., 2008. Optimisation of ultrasound-assisted extraction of phenolic compounds from wheat bran. Food Chemistry 106 (2), $804-810$.

Wijngaard, H., Brunton, N., 2009. The optimization of extraction of antioxidants from apple pomace by pressurized liquids. Journal of Agricultural and Food Chemistry 57 (22), 10625-10631.

Wijngaard, H.H., Brunton, N., 2010. The optimisation of solid-liquid extraction of antioxidants from apple pomace by response surface methodology. Journal of Food Engineering 96 (1), 134-140.

Xia, T., Shi, S., Wan, X., 2006. Impact of ultrasonic-assisted extraction on the chemical and sensory quality of tea infusion. Journal of Food Engineering 74 (4), 557-560.

Yanagida, A., Kanda, T., Tanabe, M., Matsudaira, F., Oliveira Cordeiro, J.G., 2000. Inhibitory effects of apple polyphenols and related compounds on cariogenic factors of mutans Streptococci. Journal of Agricultural Food Chemistry 48 (11), 5666-5671. 